\title{
THE PATHOLOGY OF SPAVIN.*
}

\section{S. A. Goldberg.}

\section{(Department of Comparative Pathology and Bacteriology, New York State Veterinary College at Cornell University.) \\ (A Thesis presented to the Faculty of the Graduate School at Cornell University for the Degree of Doctor of Philosophy, September, Iqr7.)}

The term spavin apparently had its origin from the Latin spavenius used by Jordanus Ruffus in the middle of the thirteenth century. Originally it indicated various pathological processes in the neighborhood of the tarsal joint. Later there were added modifying terms to designate different changes in the joint so that the terms bog, blood, or moist spavin were used in cases of a fluctuating swelling, the terms dry or bone spavin to indicate a hard swelling, and the term occult spavin as an invisible affection of the hock joint.

The classification of spavin was confusing at one time. De Solleysel used the term dry spavin for lameness resembling spavin lameness. True spavin he named ox spavin. Saunier introduced the term muddy spavin, usually occurring in horses raised in damp, marshy localities. Gibson selected the term bone spavin, which Bourgelat named callous spavin. By the term dry spavin he understood muscular and neuropathic lameness.

Up to the beginning of the nineteenth century the knowledge of the pathology of spavin was based on various theories that were in harmony with the medical view at that time, that of humoral pathology. In general, they correspond more or less closely with Gibson's idea that spavin begins by a soaking of the ligaments with moisture which condenses, forming a swelling composed of hardened glue, which later grows like the callus of a fractured bone, resembling a piece of flint without any visible pores, except the foramina for the passage of nerves and blood vessels such as are found in other bones that compose the skeleton. 
Haveman in 1805 was the first to show that in spavin the articular surfaces are diseased. He wrote, "The cause of lameness lies in the articular surfaces. The lameness begins as soon as the articular surfaces of the flat bones become denuded of cartilage. This is followed by a sort of growing together of the bones." He distinguished between the hard or bone spavin, the soft or moist spavin, and the occult or invisible spavin.

In I 850 Hertwig brought out the fact that in most instances spavin begins as a chronic osteitis and only rarely as an acute inflammation of the ligaments and bone caused by external injuries.

Thirty years later Gotti concluded that spavin originates in the bones of the hock joint. He found that the process usually begins with a very slow osteitis of the central and third tarsus and of the metatarsus. In the course of this osteitis there is a widening of the Haversian vessels, causing a nutritive disturbance of the bony connective tissue. The latter is finally transformed into plastic marrow tissue which produces a decalcification of the bone. The osteitis later leads to a chondritis characterized by a slow and continued inflammation of the articular cartilage, accompanied by active proliferation and destruction of the ground substance.

In the inflammatory process of the bone, Gotti recognized two stages. A destructive period, during which the newly formed marrow tends to spread slowly, and a regenerative period during which the newly formed marrow tends to be transformed into compact connective or bony tissue. Should the proliferating process reach the articular surfaces, it is possible for the marrow elements to be transformed into osseous tissue and lead to a true ankylosis.

$\mathrm{He}$ considered the formation of osteophytes as secondary, usually following the disorder of the joint, and developing at the time when the changes have reached the margin of the articular surfaces.

This view that spavin begins in the subchondral bone was confirmed by Eberlein, and it is accepted by most veterinarians to-day. Williams claims that spavin is a local 
manifestation of a general disease, and some French authors (Kitt) claim that the diseases through which young animals pass predispose them to this condition.

CASEs.

The discussion in this paper is based upon a study of sixty-five cases of spontaneous inflammations of joints leading to the changes described as spavin. In all cases the gross appearance was carefully studied and microscopic sections were taken from various parts of the joints. On account of the necessity of shortening this article a number of the cases were eliminated. In these cases the changes were similar to those described here, so that they did not add materially to the discussion.

Case 3. - Hock joints from a pure bred percheron foal that died during delivery.

The right hock joint contained a small amount of yellowish synovia. The capsule was of normal thickness. The synovial membrane was covered in places by fine, reddened, villous tufts. The edges of the tibial and astragalar articular surfaces were covered in places by a reticulum of blood vessels emanating from the synovial membrane, and extending into the joint for a distance of four millimeters. This growth was readily removed, leaving the underlying cartilage smooth. The deeper parts of the articular cartilages were, however, vascularized in places. This vascularization extended from the subchondral bone.

In the remaining articulations of the hock joint the synovial membranes were covered by fine, reddened villous tufts. The interosseous ligaments were edematous. There were reticular growths of vascular tissue, covering the articular cartilages around the interosseous ligaments emanating from the surface of the interosseous ligaments, and extending into the articulation for a distance of three millimeters. The thickest growth was in the articulation between the third tarsus and the metatarsus. All the cartilages were of a bluish color and free from erosions. All the bones of the hock joint were congested throughout.

The changes in the left hock joint were similar to those of the right hock joint, and similarly located.

This is evidently a case of subacute proliferative synovitis and an erosive osteoarthritis arising from both the bone and the synovial membrane.

The cause was probably an intra-uterine hematogenic infection. 
Case 4. - A full grown fetus removed from a five-year-old cow that died of septicemia, following traumatic gastritis.

The synovial membranes of nearly all the joints were hyperemic. In the left hock joint the synovia was reddened, and the cartilages were of a bluish color. In the tibio-astragalar articulation the cartilages of both the tibia and the astragalus were covered at the periphery by reticular vascular growths emanating from the synovial membrane, and extending into the joint for a distance of four millimeters.

The right hock joint showed changes similar to those of the left, excepting the synovia was yellowish.

The joint lesions in the cow were as follows: In the hock joints there were yellowish erosions in the tibiæ, and on the corresponding astragalar articular surfaces. In the stifle joints the synovia contained yellowish flocculi. There were several petechiæ in the synovial membranes and whitish calcified points in the cartilages. The cartilage of the anterior and lower ends of the femurs was soft and roughened. There were no villous tufts on the synovial membranes.

In the fetus the case is apparently similar, but not so far advanced as Case No. 3. In the cow there is apparently a sero-fibrino-hemorrhagic synovitis and a degenerative arthritis, perhaps resulting from the traumatic gastritis or of an independent infection.

In the hock joints there is either a chronic erosive arthritis, or a vestige of a previous arthritis.

Case 5. - A bay foal that died of a pyemia with multiple abscesses of the kidneys and diffuse hemorrhage of the adrenals, at the age of thirtysix hours.

In all the joints the synovial membranes were reddened, and the cartilages were of a bluish color. The synovia was of a brownish yellow color.

In the hock joints there were changes similar to those found in the other joints of the body. In addition there was a thickening of the cartilage in the center of each tibial trochlear ridge. This thickening appeared white, while the rest of the articular cartilage was bluish.

Microscopically, the thickened area was composed of a non-vascular reddish material, probably fibrin containing numerous fibroblasts, with here and there an island of cartilage. On the surface it was covered by cuboidal mesothelial cells. In places it was separated from the articular cartilage. These places were lined by cells resembling flattened epithelium. The cartilaginous matrix of the upper layers of the cartilage were stained pinkish, while that of the lower layers took a bluish stain. The cartilage contained numerous highly congested capillaries emanating from the subchondral bone (Fig. I).

In the subchondral bone the marrow spaces were greatly enlarged at the expense of the bony trabeculæ. They contained numerous congested blood vessels surrounded by fibroblasts and some marrow cells. These 
consisted of lymphocytes, fat cells, polymorphonuclear leucocytes, eosinophiles, eosinophilic myelocytes, with here and there a giant cell.

Cultures taken from the joints and from other organs showed a growth of a short, thick, non-motile, rod-shaped organism in pure culture. The colonies were grayish white, rounded, very viscid, and the center was nucleated. It produced acid and no gas in dextrose, lactose, and saccharose bouillon.

It did not coagulate milk or liquefy blood serum. There was no growth on gelatin at room temperature.

This is apparently a case of acute erosive osteoarthritis of a hematogenic origin, caused by infection.

Case 7. - Two black and white holstein heifer calves received for diagnosis. One was about two weeks, the other about four weeks old. They showed symptoms of white scours and died from a septicemia of B. coli.

In the younger calf there was subcutaneous edema and hemorrhage around both hock joints. In the anterior part of the astragalar trochlear grooves there were masses of reddened fibrin. Under the fibrin there was a large red erosion in each astragalus. Around this area the cartilage was becoming vascularized from the subchondral bone.

Microscopically, in the most affected portion the cartilage was entirely absent. In place of it there was a layer of connective tissue with congested blood vessels coming from the subchondral marrow. This was covered by fibrin containing red corpuscles and a few leucocytes. Towards the periphery the cartilage was partly gone and the remaining cartilage was covered by an exudate of fibrin and red cells. Farther away the cartilage was being vascularized from the subchondral bone.

In the subchondral bone the blood vessels were increased in number and markedly congested. The marrow spaces were increased in size to such an extent that the bony trabeculæ were entirely gone in places and in other places were very much thinner than normal. The marrow spaces contained congested blood vessels, a large amount of fibrin, a few fibroblasts and a few marrow cells with only here and there a giant cell.

In the older calf the changes were identical with that of the younger one. In addition there was beginning erosions on the corresponding tibial articular surfaces.

All the other joints of both calves were apparently normal.

These are cases of acute fibrinous synovitis and acute erosive osteoarthritis caused by $\mathrm{B}$. coli infection, probably through the umbilical vein.

Case Ir. - A heifer calf, two weeks old, received for diagnosis. She died of acute hemorrhagic enteritis.

Both hock joints contained a reddish gelatinous substance. In the tibio-astragalar articulations there were reddened erosions $2.5 \times$ I centimeters on the tibial articular surfaces. The astragalar articular surfaces were normal. 
Microscopically, in the eroded area the cartilage was nearly gone. There remained a thin imperforated layer in which the matrix took a pinkish stain. There was some vascularization, in the center as well as at the periphery of the erosion, by engorged capillaries emanating from the subchondral bone. In the cartilage that was not affected by erosion the superficial half stained pinkish, while the half toward the epiphyseal bone took a bluish stain.

In the subchondral bone the marrow spaces were enlarged and contained numerous engorged blood vessels, fat cells, fibroblasts, giant cells, various marrow cells, and some fibrin. They were larger in the center of the epiphysis than they were towards the articular cartilage, but the latter contained most of the congested blood vessels and the giant cells. The greatest amount of destruction of bone, however, was in the diaphysis, just beneath the epiphyseal cartilage. Here there was a large amount of fibrin and a large number of endothelial cells in the marrow spaces in addition to structures similar to those found in the subchondral epiphyseal marrow spaces. Here also the marrow spaces coalesced, due to absorption of some of the bony trabeculæ.

Of the other joints of the body, in the hip joints, in the posterior metatarso-phalangeal, and in the elbow joints the articular cartilages were of a bluish color. In the stifle joints the synovial membranes were pinkish and contained hemorrhages, the cartilages were bluish and the contents were gelatinous. The remaining joints were normal.

This is a case of acute erosive osteoarthritis resulting from scours in which the causative agent was apparently in the joint as well as in the subchondral bone.

Case 13. - A three-weeks-old heifer calf killed on account of scours. On autopsy there was found a fibrinous pleurisy and pneumonia as well as an acute catarrhal gastro-enteritis.

In the hock joints all the bones showed extensive erosions with the cartilages entirely gone in places. The joint cavities were filled with fibrin.

Both scapulo-humeral and both humero-radial joints were filled with fibrin and there was edema around them. The humero-radial joints showed, in addition, small erosions in the humeral and the radial articular cartilages. The remaining joints were normal.

Cultures showed a micrococcus albus, a streptococcus, and B. coli.

This is a case of an acute erosive osteoarthritis and a fibrinous synovitis, apparently caused by umbilical infection.

Case I6. - Left leg of a two-months-old colt received for diagnosis.

In the stifle joint the capsular ligament was thickened in places. The synovia was turbid and contained flocculi. The synovial membrane was almost completely covered by yellowish filiform and flattened villous tufts, varying in length from I millimeter to I centimeter. In one place two parts of the synovial membrane were adherent by a smooth band of connective tissue 8 millimeters wide, 2 millimeters thick, and 7 centimeters 
long, running across the median end of the patella and attached to the lower border of the patellar articular cartilage (Fig. 7).

In the femoro-patellar articulation the femoral articular cartilage was thinner than normal nearly throughout. This area was studded with punctiform reddened erosions. The subchondral bone was reddened. The patellar articular surface was normal, excepting a small erosion near the superior border and a fibrous attachment at the inferior border. The external lateral ligament was macerated and appeared shreddy.

In the femoro-tibial joint the cartilage on the center of the median ridge was gone for an area of $3.5 \times 2.5$ centimeters. The denuded bone was smooth and shiny and of a brownish gray color. The corresponding tibial articular surface was similarly affected for an area two centimeters in diameter. The cartilaginous disc was gone at this point, and at the periphery it was covered by villous tufts. On the lateral femoral trochlear ridge the articular cartilage was of a bluish color. There were punctiform erosions near the anterior and external border for an area of $2 \times \mathbf{~} I$ centimeters. The corresponding tibial articular surface and that of the cartilaginous disc were normal.

In the hock joint the capsule was of normal thickness. The synovial membrane was covered nearly throughout by reddened fibrous tufts varying in length from I to I.5 centimeters. Most of these were filiform, but some were flattened. Between the small bones the synovial membrane was roughened by fine reddened tufts.

In the tibio-astragalar articulation there was an area six millimeters square, in the center of the tibial trochlear ridge, slightly roughened by very shallow, punctiform depressions. There was a similar area on the median side of this ridge.

Microscopically, the cartilage contained areas where the nuclei were visible, but did not take the nuclear stain. At the periphery of these areas there were nests containing numerous cells in which the nuclei stained deeply. These areas were near the subchondral bone.

The subchondral marrow spaces were enlarged, and contained vessels engorged with blood and some fibroblasts.

The corresponding astragalar articular surface was more markedly affected. There was a purple shallow erosion $\mathrm{I} .5$ centimeters $\mathrm{x} 6$ millimeters in the trochlear groove. On the median side the erosion was slightly deeper, otherwise it was similar to the one on the corresponding tibial articulation.

Microscopically, in the deepest part of the erosion the cartilage was thinner than normal. In other places there were necrotic areas in the cartilage. Some of these areas extended from the subchondral bone to the surface of the cartilage. Others were situated near the subchondral bone and did not extend to the articular surface. At the periphery of these necrotic areas there were nests containing numerous deeply staining cartilage cells.

In the subchondral bone the changes were similar to those of the tibial articulation, but they were more marked. 
The calcaneo-astragalar joint and the articulation between the astragalus and the central tarsus were bluish in places, otherwise apparently normal.

The remaining joints of this leg were normal.

Media inoculated from the joints gave a growth of $\mathrm{B}$. coli.

This is a case of a subacute proliferative sero-fibrinous synovitis and erosive osteoarthritis apparently caused by infection.

Case 21. - A five-months-old bay colt that died of gangrenous pneumonia, ten days after an operation on a large edematous growth in the scrotal sac.

Both scapulo-humeral joints showed erosions one centimeter in diameter on the humeral and on the corresponding scapular articular surfaces. In the humero-radial joints there were large triangular-shaped erosions on the humeral and the radio-ulnar articular surfaces. In all the fetlock and the corono-pedal joints the synovial membranes were hemorrhagic and the articular cartilages showed small, rounded, reddened erosions. In the carpal joints the synovial membranes were hemorrhagic, otherwise the joints were normal.

In the right hock joint the capsular ligament was normal in thickness. The synovial membrane of the tibio-tarsal articulation was almost entirely covered with yellowish white villous tufts, varying in length from I millimeter to I centimeter. The synovial membranes of the intertarsal and tarso-metatarsal articulations were covered, in places, with short villous and flattened tufts. The interosseous ligaments were reddened by hyperemia.

There was a shallow, bluish erosion $\mathrm{I} .5$ centimeters $\mathrm{x} 6$ millimeters in the center of the tibial trochlear ridge. There was a similar erosion 3 centimeters $\times 5$ millimeters on the corresponding astragalar articular surface.

In the calcaneo-astragalar articulation there was a bluish erosion 2 centimeters $\times 2$ millimeters $x .5$ millimeter in the angle of the lateral astragalar articular facet. There was a similar, but very shallow erosion on the corresponding calcanean articular facet. The remaining articular cartilages of the hock joint were of a bluish color, otherwise apparently normal.

The left hock joint contained a little yellowish, turbid synovia with flocculi of fibrin. The capsule was of normal thickness. The synovial membrane of the tibio-astragalar articulation was covered over half its surface by villous tufts, varying in length from I millimeter to I centimeter. In the center of the tibial trochlear ridge there was a slightly noticeable erosion 1.5 centimeters $\times 7$ millimeters. The base of this erosion was covered by a thin layer of cartilage. On the corresponding astragalar articular surface there was a deeper bluish erosion 1.5 centimeters $x 4$ millimeters $x$ I millimeter.

In the calcaneo-astragalar articulation there was a purple-colored erosion I centimeter $\times 2$ centimeters $\times .5$ millimeter in the angle of the lateral 
astragalar articular facet. The corresponding calcanean articular surface was similarly, but very slightly affected. There was a flattened transparent growth of connective tissue projecting from the synovial membrane into this eroded area.

In the articulation between the astragalus and the central tarsus there was a flattened growth of connective tissue on the synovial membrane projecting into the joint cavity for a distance of one millimeter. There was a similar growth on the synovial membranes in the articulation between the central and the third tarsus, and in the tarso-metatarsal articulation.

There was a fibrous ankylosis between the central and the third tarsus that emanated from the space around the interosseous ligament and that ran antero-posteriorly for a distance of $8 \times 2$ millimeters. The cartilage immediately surrounding the ankylosed area was depressed.

The remaining articular cartilages of the hock joint were bluish, otherwise apparently normal.

Microscopically, in the shallow erosions the cartilage was thinner than normal, and covered by cells resembling flattened endothelial cells. The cartilage immediately underneath resembled fibro-cartilage, and that nearer the bone appeared normal. At the periphery of the erosion the superficial layer of cartilage took a pinkish stain, while the deeper layers stained blue.

In the subchondral bone some of the marrow spaces were enlarged and filled with numerous, very markedly congested blood vessels, some lymphoid marrow, and fat cells. Those farther away contained few congested blood vessels and fat cells.

In the deeper erosions the microscopical changes were the same, excepting more marked.

This is a case of subacute proliferative synovitis and erosive osteoarthritis, and an acute hemorrhagic synovitis and erosive osteoarthritis in some of the joints. In the articulation between the left central and third tarsus there was a chronic fibrous ankylosing osteoarthritis.

Case 22. - A black pure-bred percheron colt, six months old, killed on account of gonitis.

The left coxo-femoral articulation contained about a tablespoonful of clear yellow fluid. The cartilage of the cotyloid cavity was slightly roughened.

The left stifle contained 340 cubic centimeters straw-yellow, slightly viscid fluid with yellowish white flocculi. The lateral femoral trochlear ridge was eroded for an area of $8 \times 2.5$ centimeters. At the rim of this erosion, near the attachment of the capsular ligament, the synovial membrane was gone for an area of $7 \times 4$ centimeters. The ligament underneath was flabby and thready appearing, as if it were chewed, due probably to its being caught between the patella and the trochlear ridge as the former slipped out of its place. The rest of the capsule appeared slightly thickened. The synovial membrane was thickened by fibrous tufts, the 
larger of which were about five millimeters long. This was most pronounced at the insertion of the capsule and gradually disappeared away from that point.

At the upper edge of the erosion there were several pieces of cartilage of apparently normal structure and barely attached to it by what seemed to be threads of softened cartilage. The erosion presented a central area $4 \times$ I centimeters where the cartilage was entirely gone and the denuded bone was reddened and rough. Around this area the cartilage appeared as if it had been chewed off and was becoming smooth, probably by the friction of the slipping out of the patella.

The patella showed an erosion two centimeters in diameter on the surface corresponding to the erosion on the lateral femoral trochlear ridge. On the synovial membrane surrounding the patella there were fibrous tufts similar to those described above, except for an area five centimeters long at the external capsular attachment where the synovial membrane was normal.

In the right stifle there were subcutaneous hemorrhages, ecchymoses, for an area of $6 \times 4$ centimeters. One hundred cubic centimeters of thick, turbid, reddish brown fluid was removed from the joint. The capsule was divided into pockets so that some pockets contained clear straw-yellow fluid, while others contained the above-mentioned cloudy fluid. The pockets were all tense and under pressure. The liquid was forced out, on incision, for a distance of about three feet. The cloudy fluid coagulated on standing.

The capsule was thickened by connective tissue. There was edema around the capsule. The capsule contained ossified and chondrified areas, the largest one being I centimeter $\times 5$ millimeters. The synovial membrane was thickened by fibrous tufts, some of which were threadlike while others were club-shaped or papilliform, most of them about I.5 centimeters long, projecting into the articular cavity. In the folds of the synovial membrane there were large flattened yellowish masses of coagulated fibrin that projected into the cavity. The edges of some of these were reddened. Some of these were free, while others were attached to the capsule.

Microscopically, the masses lying free in the pockets of the synovial membrane were masses of granular, reticular, and homogeneous fibrin. On the surface of this fibrin were quite a few leucocytes and endothelial cells. In this area were seen a few cocci and rods. The masses attached to the synovial membrane were composed of connective tissue cells surrounding small blood vessels. Here and there were seen minute areas of cartilage and of bone (Fig. 9). This granulation tissue was covered by fibrin in which were seen some leucocytes.

The medial femoral trochlea was of a bluish color and the cartilage was partly covered by masses of fibrin, otherwise it was apparently normal. The lateral trochlear ridge presented an erosion at its lower half 4 centimeters x 2. 5 centimeters $x$ I millimeter. It was of a yellow color, lusterless, and studded with punctiform erosions. 
Microscopic examination of the median femoral trochlear ridge showed that the articular cartilage was being dissolved in places by vascularization from the subchondral bone and by a marked fibrinous exudate. There were also a few giant cells and some endothelial cells. In the subchondral bone the marrow spaces were enlarged to such an extent that few bony trabeculæ remained. These spaces contained a marked fibrinous exudate and many congested capillaries. The marrow cells were more numerous nearer the articular cartilage than farther away (Fig. 2).

The patella presented a small, deep, eroded area $\mathrm{I} .5$ centimeters $\mathrm{x} 8$ millimeters $\times 2$ millimeters on the surface, which was applied to the erosion on the lateral femoral trochlear ridge. On the same side and a little lower there was a mass of organized fibrin attached to the cartilage as if a line were drawn across it. This seemed to come from the synovial membrane.

Microscopically, the cartilage was apparently normal. This was covered by small blood vessels surrounded by connective tissue cells, i.e., granulation tissue. This granulation tissue varied in age, the oldest being next the articular cartilage and the youngest being covered by a thin film of fibrin about one-fourth the entire thickness of the band (Fig. 6).

In the center of the patellar erosion the cartilage was gone. In place of the subchondral bone there were fibrous connective tissue cells surrounding congested blood vessels. On the surface of this tissue there was an exudate of fibrin containing bluish granules. The marrow spaces, beneath the granulation tissue, were enlarged and contained a considerable amount of fibrinous exudate, congested blood vessels, marrow, and young connective tissue cells. Next to the bone they were lined by endothelial cells, a few giant cells, and a considerable number of osteoblasts. The cartilage on both sides of the erosion was markedly degenerated, that on one side dipping into the granulation tissue. Blood vessels were seen penetrating the neighboring cartilage. There were a considerable number of giant cells subchondrally in this region.

In the femoro-tibial joint the synovial membrane was thickened by reddened fibrous tufts. There were fibrinous masses in the folds resembling those in the femoro-patellar joint. There was in addition a greenish yellow mass of fibrin resembling a lump of fat. The cartilaginous pads appeared normal.

In the right hock joint the capsule was normal in thickness, but the synovial membrane was thickened by filiform and a few papilliform fibrous tufts. In the tibio-tarsal articulation there was a roughened erosion I centimeter $\times 5$ millimeters $\times$ I millimeter on the median astragalar trochlear ridge. On section the bone beneath the erosion was reddened for an area of two millimeters. Anterior to this erosion the cartilage had been worn off for an area of $\mathrm{I}$ centimeter $\mathrm{x} 6$ millimeters wide. There were several punctiform erosions on the lateral trochlear ridge. There was also an erosion 4 centimeters $\times 4$ millimeters $\times .5$ millimeter in the trochlear ridge. 
Microscopically, in the center of the erosion on the median ridge, the cartilage was almost gone, but little connective tissue being in its place. On each side of this area the cartilage was replaced by connective tissue. There was also a replacement of bone by connective tissue. The fibrillæ of the former were of a bluish tint while those of the latter were stained red. In the marrow spaces just beneath the articular cartilage there were proliferating capillaries distended with blood with here and there a giant cell. There was also some fibrinous exudate. In the area where the cartilage had been replaced by connective tissue, some of the vessels projected into this tissue. Near this area there were seen several nests of proliferating cartilage cells. The marrow spaces farther away were markedly enlarged at the expense of the bony trabeculæ. They were filled with fibroblasts, congested capillaries, and some fibrinous exudate.

In the calcaneo-astragalar articulation there was a shallow erosion $8 x$ 3 millimeters in the angle of the lateral astragalar articular facet. There was a similar but smaller erosion on the corresponding calcanean articular facet.

In the articulation between the astragalus and the central tarsus there was a flattened growth of connective tissue on the synovial membrane projecting into the joint cavity for a distance of one millimeter. There was gelatinous material around this growth.

The articulations between the central and third tarsus and between the third tarsus and metatarsus showed the same changes as those in the articulation between the astragalus and the central tarsus. On section of the hock, the third tarsus was markedly reddened for an area of three centimeters and throughout its thickness. There was a reddened area in the calcaneum forming a rim under its articular cartilage.

All the other joints of the body were apparently normal.

In cultures made from the joints a short streptococcus, staphylococcus. albus, and Ps. pyocyaneus, were obtained.

In this case, apparently, we have in the left stifle a marked serous and proliferative synovitis of long standing with a secondary erosive osteoarthritis.

In the right stifle there was apparently an acute sero-fibrinous synovitis which was being transformed into a chronic erosive osteoarthritis and proliferative synovitis.

In the right hock joint there was an erosive osteoarthritis and proliferative synovitis.

The cause seems to have been an infection perhaps through the navel.

Case 26. - A four-year-old Guernsey cow killed on account of lameness. and general emaciation due to a chronic catarrhal enteritis.

In the right hind leg the coxo-femoral joint was normal. In the stifle joint there were erosions on the distal end of the femur on the facets that are applied to the semi-lunar cartilages. The erosions were shallow and extended about two centimeters in diameter. The center of the semi-lunar 
cartilages showed fibrillation. The corresponding articular surface of the tibia showed fibrillary degeneration. There was a normal amount of yellowish viscid synovia in the joint. The synovial membrane was thickened by grayish tufts. The femoro-patellar joint was apparently normal, excepting a small erosion about five millimeters in diameter on the lower border of the patella. Cultures taken from this joint remained sterile.

In the hock joint the cartilages of all the bones were eroded in places, the remaining cartilage appeared reddened.

The other joints were apparently normal, excepting the cartilages were reddened.

In the left hind leg the coxo-femoral joint was apparently normal.

In the femoro-patellar joint the synovial membrane was roughened and covered by punctiform hemorrhages. Reddened fibrinous masses were present in the joint. These were adherent to the synovial membrane. The articular cartilages were of a bluish color, and lusterless. There was a hemorrhagic area 2 centimeters $\times 4$ millimeters on the femur, above and immediately posterior to the articular cartilage.

In the femoro-tibial joint the capsule was thickened. The synovial membrane was of a brownish color, and it was thickened by papilliform tufts. The anterior surface of the external condyle of the femur was eroded for an area of 2 centimeters $\times 1.5$ centimeters $\times 2$ millimeters. This area was denuded of its articular cartilage. The denuded bone was smooth and shiny. Adjacent to and posterior to this area there was a similar eroded area from which the cartilage was not entirely worn away. On the internal side of the median condyle there was a shallow erosion about 1.5 centimeters $\times 5$ millimeters $\times .5$ millimeter. The semi-lunar cartilages showed fibrillation in places. The tibial articular cartilages were roughened and of a bluish color.

Media inoculated from the femoro-patellar joint gave a growth of micrococcus albus, aureus, and citreus.

The hock joint showed erosions in all the articulations.

The lower joints were apparently normal, excepting the cartilages were slightly reddened.

In the fore legs the elbow joints showed erosions about $2.5 \mathrm{x}$ I centimeters on both the radio-ulnar and the humeral articulations. All the other joints were apparently normal.

This is a case of a chronic erosive osteoarthritis and proliferative synovitis. There was also an acute fibrino-hemorrhagic synovitis of the left femoro-patellar articulation. The latter was evidently caused by a micrococcus infection. In the former the cause is unknown.

Case 30. - An eight-year-old iron-gray percheron mare that died with fistulous withers that extended to the spinal cord.

In both humero-radial joints there were erosions 2.5 centimeters long and 2 centimeters wide on the humeral articular surfaces. There were similar erosions on the corresponding radio-ulnar articulations. 
In the right hock there was a little yellowish clear synovia. The capsule was apparently normal. The synovial membrane was thickened by whitish villous tufts over about two-thirds of its surface. These varied from I millimeter to 2 centimeters in length. Some were filiform, while others were flattened.

There was an irregularly shaped bluish erosion $\mathrm{I} .5$ centimeters $\mathrm{x} 5$ millimeters $x$ I millimeter in the center of the tibial trochlear ridge. On the corresponding astragalar trochlear groove there was an erosion I centimeter square and I millimeter deep on the anterior and lower border, and an erosion $5 \times 2 \times .5$ millimeters near the posterior border. There was an erosion $\mathrm{I}$ centimeter $\mathrm{x} 6$ millimeters $\mathrm{x}$ I millimeter on the median ridge of the astragalar trochlea. On the lateral ridge the cartilage was dull and softer than normal.

In the calcaneo-astragalar articulation there was an erosion $\mathbf{I} .5$ centimeters $\mathrm{x}$ I centimeter $\mathrm{x} .5$ millimeter on the external astragalar articular facet. There was a similar erosion on the corresponding calcanean articular facet. In the base of this erosion there was a whitish growth of connective tissue. There was an erosion I centimeter $\mathrm{x} 5$ millimeters $\mathrm{x} .5$ millimeter on the median astragalar articular facet, and a similar erosion on the corresponding calcanean articular facet.

In the articulation between the astragalus and the central tarsus the cartilage was roughened along the anterior border varying in width from 3 to 6 millimeters. Near the median border and immediately behind the roughened surface there was a whitish thickened roughened area I centimeter $\times 5$ millimeters $\times \cdot 5$ millimeter at its thickest place. The corresponding articulation of the central tarsus was similarly affected. On drying the cartilage became dull yellow in color and extremely brittle, probably due to presence of lime salts in the cartilage. The astragalar and calcanean subchondral bones were reddened, varying in width from I to 5 millimeters, the reddening being I millimeter away from the cartilage. The periosteum near the upper and anterior articular margin of the central tarsus was thickened to about one millimeter. It was of a whitish color and soft in consistency.

The articular surfaces between the central and the third tarsus were roughened.

There was a fibrous ankylosis between the third tarsus and the metatarsus for an area of about $8 \times 5$ millimeters at the anterior border of the articulation, not involving the capsular ligament. There was a groove about I millimeter deep and .5 millimeter wide around the fibrous tissue. There was an erosion $I$ centimeter $\times 5$ millimeters $x .5$ millimeter on the third tarsus at the anterior border of the interosseous ligament. There was a similar erosion on the corresponding metatarsal articular surface. The subchondral bone was reddened in places.

In the left hock joint the synovial membrane was not so extensively affected by fibrous tufts as that of the right hock joint. There was a similar erosion on the tibial trochlear ridge. On the corresponding astragalar articular surface the erosion in the trochlear groove was 3.5 
centimeters $\mathrm{x}$ I centimeter $\mathrm{x}$ I millimeter. There was an erosion 8 millimeters in diameter and $I$ millimeter deep on the median astragalar trochlear ridge. There was an extensive roughening of the cartilage around the latter erosion.

In the astragalo-calcanean articulation the changes were similar to those of the right hock and similarly located.

In the articulation between the astragalus and the central tarsus the synovial membrane on the median side of the articulation was thickened by a flattened growth of connective tissue, projecting into the joint cavity for a distance of two millimeters. The articular cartilages in this place were roughened by shallow erosions for a distance of $2 \times$ I centimeters. The cartilage in this place was bluish. The remaining articular cartilage was apparently normal.

In the articulations between the central and the third tarsus and between the third tarsus and the metatarsus the articular cartilages near the median border were roughened and bluish in color. The subchondral bones were reddened.

The remaining joints of the body were apparently normal.

Microscopically, in the center of the right tibial erosion the cartilage was nearly all gone, but the lowermost layer remained. Above that there were individual cartilage cells with a pinkish staining cell body and intercellular substance. This was covered by what appeared to be a mass of necrotic tissue in which the nuclei have disappeared. In this mass there were scattered fibroblasts. On the surface there was a thin layer of fibroblasts and adult connective tissue cells. The zone of calcification has not been broken except in one point, at the periphery of the erosion, where it has been destroyed by subchondral congested blood vessels surrounded by fibroblasts. The cartilage in this place showed evidence of proliferation. There were masses of bluish staining cartilage cells and there were nests containing numerous cells. The cartilage above this area was degenerated but intact. In the subchondral bone under the eroded area the marrow spaces were enlarged and filled with fat cells, congested blood vessels, and fibroblasts. Outside of this erosion the cartilage was nearly normal and the subchondral bone was somewhat denser than normal and slightly congested. A few of the subchondral Haversian canals were filled with congested blood vessels and fibroblasts.

In the left tibial erosion the cartilage was nearly all gone, including the lowermost layer. There remained only a few cartilage cells in the center of the erosion. In the place of the cartilage there was a thin layer of fibroblasts and old connective tissue cells. At the periphery the bone projected nearly to the articular surface. The other changes were similar to those in the right tibia.

The right astragalar erosion was more advanced than that of the right tibia. It was deeper, involving the bone more, and the connective tissue layer was narrower. The subchondral bone and the surrounding bone and cartilage were similar to those of the tibia. 
In the articulation between the central and the third tarsus there were subchondral foci of necrosis in the places that macroscopically appeared roughened. These foci involved in places the lowermost layers of the cartilage. In other places the foci of necrosis extended for a considerable distance into the bone. The cartilage covering these areas showed marked degeneration. The cartilage was broken only at one point where the bone was extensively involved. There was also degeneration of the cartilage near the synovial membrane. The subchondral bone, aside from the necrotic areas, was dense and the Haversian canals were only here and there enlarged and irregular in shape. All the Haversian canals were, however, filled with fibroblasts, adult connective tissue cells, and congested blood vessels. Some of the enlarged canals also contained fibrin and some lymphocytes and a few of them were filled with endothelial cells.

In the articulation between the central tarsus and the astragalus the cartilage next to the synovial membrane was thickened and showed fibrillary degeneration, that towards the center of the joint was thinner and degenerated. The subchondral bone was dense and congested. The neighboring synovial membrane was markedly congested and showed proliferation of mesothelial cells and blood vessels. The periosteum of the central tarsus was thickened by large cells resembling cartilage cells, lying in rows parallel with the fibers of the attached ligaments. These cells were lying singly, and in very few places they appeared in nests of two, probably due to multiplication. In several areas the periosteum of the third tarsus was similarly affected. The other parts were normal.

This is a case of degenerative, erosive, and fibrous ankylosing osteoarthritis and proliferative synovitis. Some of the changes, such as fibrillary degeneration and the proliferation of the synovial membrane and of the periosteum, indicate a mild irritation. The other changes, including the fibrinous exudate, the hyperemia, and the necrosis in the subchondral bone indicate a severe irritation. They also indicate infection. It is possible that this condition was caused by metastasis of microörganisms from the fistulous withers. This at first produced mild irritation, and with the lowering of the resistance of the animal, the microörganisms came to these joints in greater number and produced a severe irritation accompanied by the acute changes.

The degeneration without any break in the continuity of the cartilages and the proliferation of the synovial membranes seem to indicate that the irritant was perhaps first in the joint. The necrotic foci and the other changes in the subchondral bone seem to indicate that there were, perhaps later, metastatic foci in the subchondral bone.

Again, in the apparently unaffected parts of the articulations the subchondral bones were denser than usual. This perhaps indicates that this density of the bone, the erosions in the tibio-tarsal articulations, and the tufts on the synovial membranes are vestiges of a previous inflammation. It may also be that in this animal the bones were naturally denser than usual. In the latter case the conclusion that in this case the irritant was 
both in the subchondral bone and in the joint cavity, or perhaps that it was in the joint cavity first and later in the subchondral bone also, may be justified. In the former case, where the assumption is that the mild changes are due to a previous inflammation, it is possible that in both inflammations the origin was in the subchondral bone.

Case 35. - A fifteen-year-old red roan gelding that died with a gangrenous pneumonia.

In each scapulo-humeral joint there was a triangular erosion on the humeral heads. The remaining cartilages were bluish. In the humeroradial joints there were erosions 4 centimeters $\times 2$ centimeters $\times 3$ millimeters on the humeral, and on the corresponding radio-ulnar articular surfaces. The rest of the cartilage was bluish. In the carpal joints the synovia was reddish. The cartilages were bluish and eroded in places.

In the stifle joints the synovial membranes were thickened and roughened by a reticular growth of connective tissue.

On the outside, in front and above the left hock, there was a swelling $3 \times 2 \times 2$ centimeters, composed of edematous connective tissue.

The joint cavity contained about a tablespoonful of yellow viscid synovia. There was a small pocket on the external side containing a mass of partly organized fibrin.

The synovial membrane was thickened anteriorly by reddish villous tufts, about one centimeter long. Posteriorly the synovial membrane was similarly affected, except that the tufts were yellowish. The articular cartilages of the tibio-astragalar joint were of a slightly bluish tinge in places. There was a very shallow erosion, 6 centimeters long and 2 millimeters wide, in the astragalar groove. There were two punctiform erosions on the corresponding tibial trochlear ridge. On section there was marked subchondral hyperemia in all the bones of this joint.

In the calcaneo-astragalar joint there was an erosion 2 centimeters $x$ I centimeter $x$ I millimeter on the lateral astragalar and on the corresponding calcanean articular surfaces. This area was filled with a yellowish brown gelatinous mass. There was a smaller erosion on the median facets of these bones, partly filled with a similar mass. The remaining cartilages were bluish in places. There was a shallow erosion six millimeters in diameter on the astragalus near the interosseous ligament, and a similar erosion on the corresponding articular surface of the central tarsus. The articular cartilages of the third tarsus and of the corresponding articular surface of the metatarsus were roughened in places.

On the external surface of the right hock there was a fluctuating swelling $6 \times 4 \times 2$ centimeters on the median side posterior to the tibia, just above the articulation. On opening, it showed that it was a dilatation of the articular capsule at that point. The contents were synovia, and a free irregular mass 2.5 centimeters $\times 2$ centimeters $\times 3$ millimeters, composed of shreds of fibrin mixed with synovia. There was also a partly organized mass of fibrin adherent to the synovial membrane. The synovial membrane was thickened by villous tufts that were anteriorly of a reddish color 
and posteriorly grayish. The dilated part also was lined by villous tufts. The tibial and astragalar articular cartilages were of a slightly bluish color, and contained grooves running from before backwards and parallel to each other. These grooves were $I$ to 6 millimeters apart, each being I millimeter wide.

On section of the hock, there was marked hyperemia subchondrally in all the bones.

There were several shallow erosions in the calcaneo-astragalar articulation. The remaining cartilages were bluish in places, otherwise normal.

Microscopically, in the erosion on the left astragalar trochlea the cartilage was thinner than in the other parts of the articulation. The remaining cartilage in the eroded area, as well as the surrounding cartilage, showed fibrillary degeneration. The subchondral bone was normal (Fig. 3). In the right tibio-tarsal articulation the grooves were of various depths, varying from places that showed a dent in the articular cartilage to those in which the cartilage has entirely disappeared, leaving the subchondral bone denuded of cartilage. The remaining articular cartilage showed fibrillary degeneration. The cartilage showed in many places nests filled with numerous cartilage cells in which the nuclei were very small. The subchondral bone showed slight congestion.

In all the other joints of the body the cartilage was of a bluish color, otherwise apparently normal.

This is evidently a case of subacute fibrinous synovitis and degenerative erosive arthritis. This originated apparently in the joints, since the subchondral bones are normal and there is no break in the continuity of the cartilage.

Case 39. - An aged sorrel mare that died with a ruptured diaphragm.

In the left scapulo-humeral joint there was a yellowish erosion I centimeter in diameter and I millimeter deep on the scapular articular surface. There was a similar erosion on the corresponding humeral articular surface. In the humero-radial joint there was a large, yellowish erosion on the radio-ulnar articular surface and a similar erosion on the corresponding humeral articulation. On the latter articular surface there were also small, scattered erosions, varying in size from 2 millimeters to I centimeter in diameter and .5 to 2 millimeters deep. In the fetlock joint there were small depressions one millimeter in diameter in the groove of the first phalanx. In the center of these depressions there were whitish, calcified points. The remaining articular cartilage was apparently normal.

In the right hock joint the synovial membrane was thickened by villous tufts. There was a yellowish erosion 2 centimeters long, I centimeter wide, and I millimeter deep, in the center of the tibial trochlear ridge. There was a yellowish erosion 4 centimeters $\times 3$ millimeters $\times .5$ millimeter in the astragalar trochlear groove. There was an erosion I.5 centimeters $x$ I centimeter $x \cdot 5$ millimeter on the internal face of the lateral trochlear ridge. Surrounding this there were several punctiform erosions and one white calcified point about .7 millimeter in diameter. 
In the calcaneo-astragalar articulation there was a whitish and yellowish erosion 2 centimeters $x 5$ millimeters $x \cdot 5$ millimeter on the lateral astragalar articular surface. There was a yellowish erosion 5 millimeters square and .5 millimeter deep on the median astragalar articular surface. There were similar erosions on the corresponding calcanean articular surfaces. The remaining articular surfaces were bluish in places, otherwise apparently normal.

Microscopically, in the erosions the zone of cartilage next to the bone was the only cartilage left. The rest of the cartilage was gone. Its place was taken by a homogeneous pinkish staining substance containing connective tissue cells. At the periphery of the erosion the upper layers of cartilage cells were degenerated. In the subchondral bone the marrow spaces were enlarged and filled with fat cells and congested blood vessels.

In the left tibio-astragalar articulation the synovial membrane and the tibial trochlea showed changes similar to those in the right hock joint. There was a yellowish erosion 3 centimeters $x$ I. 2 centimeters $\times$ I millimeter in the astragalar trochlear groove. There was an erosion six millimeters in diameter in the middle of the median trochlear ridge. The subchondral bone of this articulation was reddened.

In the calcaneo-astragalar articulation there was an erosion $8 \times 5 \times \cdot 5$ millimeters on the lateral calcanean articular facet and a similar erosion on the corresponding astragalar articular surface. The median articular facets were normal, except at the lower border for an area of I centimeter $\times 5$ millimeters where the cartilage was of a purple color.

The articulation between the astragalus and the central tarsus was normal, excepting a few spots where the cartilage was of a purple color. These spots were irregularly distributed over the entire articular surface.

In the articulation between the central and the third tarsus the anterior and median margins of the articular cartilages were eroded. The borders of the erosions were irregular. In some places there were depressions and in others there were elevations. The elevated areas in the erosions were due to a growth of whitish connective tissue. In places the two bones were grown together by connective tissue. In these places the synovial membrane was grown fast to the bones. This area was about eight millimeters wide.

In the center of the third tarsus there was a yellowish, roughened, raised calcified area one millimeter in diameter. There was a depression on the corresponding articular surface of the central tarsus. There was a shallow, roughened erosion five millimeters in diameter in the posterior part of the third tarsus and a similar erosion on the corresponding articular surface of the central tarsus.

In the articulation between the third tarsus and the metatarsus the anterior border was roughened for a distance of about two millimeters in width. Otherwise the articular cartilages were normal.

The hind fetlock joints were normal, except that the synovial membranes were covered with reddened villous tufts. In the left hind leg, in the articulation between the first and second phalanges, the two bones were 
grown together by partial osseous ankylosis. There was also a periarticular paraostosis in the form of a smooth bony growth $\mathrm{I} .5$ centimeters thick and 5 centimeters long. Between the bones and the bony outgrowth there was a thin layer of connective tissue. There was a ringbone in the right hind leg on the distal end of the first phalanx not involving the articulation.

The right fore leg was not examined.

The remaining joints were apparently normal.

This is a case of a chronic erosive osteoarthritis and proliferative synovitis with a chronic fibrous ankylosing osteoarthritis of the left hock joint and a chronic osseous ankylosing osteoarthritis and periarthritis of the left phalangeal joint. The subchondral and subsynovial hyperemia was probably due to the cause that produced the death of the animal.

Case 40. - An aged bay mare that was killed on account of chronic pulmonary emphysema.

In both coxo-femoral joints the articular cartilages of both the cotyloid cavities and the corresponding femoral heads were thickened, wrinkled, and of the consistency of soft rubber. The synovial membranes were normal.

In the left hock joint the synovia was normal. The capsular ligament was normal in thickness. The synovial membrane was thickened and roughened by a reticular growth of connective tissue.

In the center of the tibial-trochlear ridge there was an erosion I centimeter $\times 5$ millimeters $x \cdot 5$ millimeter. In the base of this erosion there was a growth of whitish connective tissue. There was a similar erosion in the corresponding astragalar groove. There was considerable roughening of the cartilage on the lateral articular surfaces of this joint.

In the calcaneo-astragalar articulation there was an erosion I centimeter $x_{4}$ millimeters $x_{I}$ millimeter in the angle of the lateral astragalar articular facet. The base of this erosion was yellowish, containing reddish points in several places. There was a similar erosion on the corresponding calcanean articular facet. This erosion emanated from the space surrounding the interosseous ligament.

The articulation between the astragalus and the central tarsus was normal.

In the articulation between the central and the third tarsus there was slight roughening on the anterior and median margin of the articular cartilages. There was fibrous ankylosis near the posterior end of the interosseous ligament for an area of four millimeters in diameter. The synovial membrane of this articulation was normal.

There was fibrous ankylosis between the central tarsus and the os tarsale I. et II. at the upper border, for a distance of two millimeters in diameter involving the synovial membrane. The cartilages around the ankylosed area were roughened by erosion. The remaining articular cartilages of the hock joint were normal. 
In the right hock joint the tibio-astragalar articulation was similar to that of the left, except there was not so much connective tissue in the erosions. There were also a few reddened fibrous tufts on the synovial membrane in addition to the thickening of the latter by reticular connective tissue.

The calcaneo-astragalar articulation was similar to that of the left hock, except the erosion contained a growth of whitish connective tissue.

In the articulation between the central and the third tarsus there was fibrous ankylosis near the posterior end of the interosseous ligament for a distance of $5 \times 2$ millimeters running in an antero-posterior direction.

There was fibrous ankylosis between the central tarsus and the os tarsale I. et II. similar to that of the left hock joint.

The remaining articular cartilages of the hock joint were normal.

The remaining joints of the hind limbs were normal. The fore limbs were not examined.

Microscopically, in the ankylosed area the synovial membrane was obliterated. The bones were grown together by a homogeneous nonvascular mass containing degenerated cartilage cells and connective tissue cells. Some of each subchondral bone was replaced by that tissue. There was, however, a line of demarcation between the bone and this mass of tissue. This line stained blue, and was continuous on both sides of this mass, except at one point, where it was broken by an enlarged Haversian canal. This blue line was composed of cartilage cells, which in places showed evidence of proliferation. In the part of the joint that was not grown together the upper layers of the articular cartilages, on both surfaces, were necrotic. The layers next to the subchondral bones were degenerated. In the subchondral bones the Haversian canals were enlarged and irregular in shape. They were filled with fibrin, congested blood vessels, newly formed blood vessels, endothelial cells, fat cells, and fibroblasts. The periosteum in the vicinity of the ankylosed area was thickened by large cells lying in rows parallel with the fibers of the attached ligaments.

This is a case of a chronic erosive and fibrous ankylosing osteoarthritis, and proliferative synovitis.

Case 4I. - The hock joints of an aged horse that died of swamp fever. In the right hock joint there was a bony outgrowth, $3 \times 12 \times$ I centimeters, on the median side over the articulation between the upper and middle rows of tarsus. The astragalo-calcanean articulation was obliterated throughout its extent, excepting for a small area five millimeters long at the upper border. The obliterated part was reddened throughout its extent, the articular cartilages were apparently gone, and in places it seemed as if the two bones were grown together by fibrous tissue. In the articulation between the astragalus and the central tarsus there was an area one centimeter long immediately anterior to the interosseous ligament where the articular cartilages were gone and the bones were grown together by fibrous tissue. There was slight hyperemia around this area. 
The subchondral bone was reddened for an area extending from this ligament to the bony outgrowth on the median side. On the other side of the ligament the subchondral bone, as well as the articular cartilages, were apparently normal. There was a very shallow, uneven erosion I2 $\times 5$ millimeters in the astragalar trochlear groove, in the center of which there were whitish areas of connective tissue. There was no reddening of the subchondral bone in this eroded area.

On the tibial trochlear ridge there was a whitish area, 3 centimeters $x$ 6 millimeters $\times 3$ millimeters, that appeared as if an erosion was in this place and it had become healed, so that now the ridge was smooth throughout its extent. In the median trochlear groove there was a white growth of connective tissue on the articular cartilage $15 \times 5$ millimeters. There was a growth three centimeters thick on the median side of the tibia immediately above the articulation. It was composed of fibrous tissue and cartilage.

Microscopically, in the periarticular bony outgrowth the marrow spaces in the central part of the newly formed bone were large and filled with congested blood vessels, fibrin, fibroblasts, and lined with fibroblasts and here and there a giant cell. In place of the synovial membrane there was an area of cartilage cells arranged in rows perpendicular to the articular surfaces. Next to this area the two articular surfaces were grown together by cartilage and connective tissue cells. Toward the center of the articulation there was a considerable amount of a pinkish staining homogeneous substance, apparently the remains of the upper layers of the cartilage. The cartilage next to the subchondral bone was intact except near the edge of the articulation. The periosteum on each bone under the newly formed bone was intact. In the subchondral bone at the articular border the Haversian canals were enlarged and filled with fibroblasts and congested blood vessels. Toward the center of the articulation the Haversian canals were enlarged and filled with congested blood vessels and fat cells. On the outside the newly formed bone was covered by a large amount of connective tissue.

In the calcaneo-astragalar articulation, at the proximal border, the upper layers of the cartilage were pinkish and homogeneous, and the two articular cartilages were separated by the joint space. Approaching toward the center of the articulation the cartilages were the same, but the joint space was filled with connective tissue cells and fibroblasts. Farther down the necrotic parts of the cartilage were gone. In their place was a mass of connective tissue cells and fibroblasts containing numerous congested blood vessels running in various directions. On each side of this mass were several bony lamellæ lined by osteoblasts and attached to the lower layers of cartilage. The joint space was of course obliterated (Fig. 8). Still farther down there was complete osseous ankylosis, with here and there a few cartilage cells remaining. In this part the marrow spaces were filled with fibroblasts and congested blood vessels. In the rest of the joint there was complete osseous ankylosis. In this part the bone was somewhat denser than the surrounding bone, and the marrow spaces 
were filled with fibroblasts, congested blood vessels, fibrin, and fat cells. In the surrounding bone the marrow spaces were filled with fat cells and a few congested blood vessels. The neighboring periosteum showed slight proliferation.

In the articulation, between the astragalus and the central tarsus near the interosseous ligament, there was a small area of osseous ankylosis in which the bone was denser than the surrounding bone, and the Haversian canals were filled with fibroblasts. Around this area the articular cartilages were nearly normal, and the surrounding bone was slightly congested. There was also a small area of fibrous ankylosis in which the fibrous tissue contained numerous fibroblasts and congested blood vessels of various sizes. Next to the bone there were areas of cartilage. Around this ankylosed area the upper layers of the cartilages have gone, and the layers next to the bones were covered by granulation tissue similar to that in the ankylosed area. This tissue was being transformed into bone. This was shown by the presence of bony lamellæ applied to the remaining cartilage and lined by osteoblasts. In the subchondral bones the Haversian canals were enlarged and irregular in shape. They were filled with fibroblasts, fibrin, and congested blood vessels (Fig. II).

In the white-colored area in the center of the tibial trochlear ridge the cartilage was entirely gone. Its place was taken by connective tissue containing some cartilage cells. The usual zones of articular cartilage were absent. At the periphery there were nests of proliferated cartilage cells. In the surrounding cartilage the upper layers showed degeneration. In the subchondral bone some of the Haversian canals were enlarged, irregular in shape, and contained congested blood vessels and fibroblasts.

In the left hock the capsular ligament was slightly thickened. The synovial membrane was smooth, excepting along the margins where the various bones were in apposition. Along these margins the synovial membrane was thickened by whitish fibrous tufts varying in length from I millimeter to I centimeter, the longest being in the tibio-astragalar articulation.

There was a yellowish erosion $\mathrm{I} .5$ centimeters $\mathrm{x} 6$ millimeters $\mathrm{x}$ I millimeter in the center of the tibial trochlear ridge. There was a similar erosion 3 centimeters $\times 5$ millimeters $\mathrm{x}$ I millimeter on the corresponding astragalar articular surface. The remaining articular cartilages were roughened in places and softer than normal. They had a sort of velvety appearance.

In the calcaneo-astragalar articulation there was an erosion I centimeter $\times 8$ millimeters $\times \mathrm{I}$ millimeter on the lateral astragalar articular facet. At the lower border of this erosion there was a growth of connective tissue. There was a partly reddish and partly yellowish erosion $6 \times 2 \times .5$ millimeters on the median astragalar articular facet. There were similar erosions on the corresponding calcanean articular facets.

The articulation between the astragalus and the central tarsus was apparently normal. 
In the articulation between the central tarsus and the third tarsus there was complete osseous ankylosis at the lateral and anterior aspects of the articulation, not involving the capsular ligament or the synovial membrane. In the ankylosed part the bone was denser than the porous bone of that part, but not as dense as the cortical bone. The ankylosed area was somewhat reddened. Near the middle of the articulation the bones were partially ankylosed, some of the cartilage remaining intact. The median margin was normal, but the cartilages near the median margin were roughened by shallow erosions.

The remaining articulations of the hock joint were apparently normal.

The lining of the calcanean bursa was slightly roughened throughout. On the lateral side of the tuber calcis for an area of $3 \times 2$ centimeters there were erosions surrounded by an excessive growth of connective tissue.

This is a case of a chronic erosive, fibrous, and osseous ankylosing osteoarthritis and proliferative synovitis, as well as chronic ossifying periarthritis.

Case 42. - An aged gray mare suffering from spavin of both hock joints. Killed by chloroform.

In the left coxo-femoral joint the articular cartilages of both the cotyloid cavity and the head of the femur were thickened, wrinkled, and of the consistency of soft rubber. On section they showed fibrillation of the cartilage. The subchondral bone was apparently normal.

In both stifle joints and in the left carpal joint there were old yellowish erosions of the articular surfaces.

In both hock joints in the articulations between the astragalus and the central tarsus the articular cartilages were entirely gone from both articular surfaces. The denuded bone was yellowish, smooth, and denser than normal, except in a small area where the denuded bone was roughened and reddened. In the right hock joint there was in addition fibrous ankylosis in several areas in the articulation between the central and third tarsus.

Microscopically, the surface of the denuded bone was denser than normal. Towards the center of the bone the Haversian canals were enlarged, irregular in shape, and filled with granulation tissue.

All the other joints were apparently normal.

This is a case of a chronic degenerative arthritis and a chronic erosive and fibrous ankylosing osteoarthritis.

Case 43. - A twenty-five-year-old buckskin mare extremely lame on left hind limb. Killed by chloroform. There were fibrous tufts and adhesions on the pleura and the peritoneum.

In the left coxo-femoral joint there were yellowish erosions 1.5 centimeters in diameter on the corresponding articular surfaces. Both stifle joints showed slight erosions. 
Both hock joints were enlarged. The left was hard, while the right was fluctuating. There was osseous ankylosis between the two lower rows of tarsus and the metatarsus in both hock joints. In the left tibioastragalar articulation there was a considerable amount of reddened synovia containing flocculi of fibrin. The synovial membrane was reddened, roughened, and thickened by a partly organized fibrino-hemorrhagic exudate. There was a reddish erosion $3 \times 1$ centimeters in the astragalar trochlear groove. There was a reddened triangular-shaped erosion on the median and an erosion I centimeter $\times 4$ millimeters on the lateral astragalar trochlear ridge. There were corresponding erosions on the tibial articulation. In the right tibio-astragalar articulation the capsule was distended by a yellowish turbid liquid that coagulated on standing. A smear showed it to contain numerous polymorphonuclear leucocytes.

Media inoculated from the left hock joint gave a growth of staphylococcus albus in pure culture. From the right hock joint there was a pure culture of B. coli producing gas in dextrose, lactose, and saccharose.

This is a case of a chronic erosive and osseous ankylosing osteoarthritis apparently inactive at this time. There is also an acute fibrinohemorrhagic synovitis and erosive osteoarthritis in the left hock joint, and a sero-purulent synovitis of the right hock joint.

The cause of the long-standing condition cannot be determined at this time. The acute conditions were apparently caused by infection.

\section{DISCUSSION.}

At the present time the term spavin stands for a chronic ankylosing intertarsal and tarso-metatarsal osteoarthritis, with or without a chronic periarticular ossifying periostitis. It is supposed to originate in the subchondral bone as a rarefying ostitis, and to spread to the articular cartilage, producing erosions and ankylosis, and to the periosteum, producing exostoses.

In the sixty-five cases studied the pathological changes varied considerably. In the capsular ligament the early changes found were infiltration of polymorphonuclear leucocytes in two cases. In others, the capsular ligaments were thickened by a serous exudate and hemorrhage, while some showed round cell infiltration. In those of longer standing the most marked change was a thickening of the capsule by a production of connective tissue. In addition, there were in this connective tissue areas of cartilage and of bone. This is seen in the stifle joint, Case 22. In one case the capsular ligament was entirely ossified (left hind ring bone, Case 39), 
and in two instances one side of the capsular ligament was ossified (left stifle, Case I6, and right hock joint, Case 4I).

In the synovial membrane the early changes were hyperemia and exudation. In some instances there were, in addition, petechial hemorrhages on the synovial membrane. The exudate was purulent, sero-purulent, and fibrino-purulent, respectively.

In many instances the exudate was mostly fibrin, and in still others there was a serous exudate. In two cases there was a sero-hemorrhagic and a sero-fibrino-hemorrhagic exudate. The fibrinous exudate was in some cases free, while in others it was firmly adherent to the synovial membrane. In those instances where the fibrin was adherent it was brought about by an organization of the fibrin by connective tissue and blood vessels, arising from the synovial membrane. In one case there were areas of cartilage and of bone in this granulation tissue (Fig. 9). Many of these were in the form of small, round bodies attached to the synovial membrane by a small, villous outgrowth. This suggests a possibility of one of the ways in which free bodies may occur in a joint. Such a free body was found in one case to be composed of cartilage, the center of which had begun to ossify.

Of the degenerative changes observed in the synovial membrane nearly all were of the nature of cloudy swelling of the lining mesothelial cells. This was rarely observed. As a rule the changes were proliferative instead. Necrosis of the synovial membrane was not found in these low-grade forms of arthritis.

The proliferative changes of the synovial membrane were usually in the form of villous tufts varying in length from .05 to two centimeters. These tufts were composed of various sized blood vessels surrounded by young and old connective tissue cells and covered by mesothelium (Fig. 7). Their appearance varied with the age of the process. In the early stages these tufts were small and reddened. In later stages they were longer and of a brownish color. In long standing cases they were whitish in color and composed mostly of adult connective tissue with a few blood vessels, and covered 
by mesothelial cells. Occasionally they were found inactive, i.e., they were the remains of a former inflammation. In these there were no fibroblasts. In many of the cases the proliferation of tissue was in the form of a connective tissue network on the synovial membrane. In several instances there were masses of connective tissue forming adhesions of different parts of the synovial membrane. In three cases of short duration there were outgrowths of blood vessels from the synovial membrane forming thin reddened arborous films on the edges of the articular surface (Fig. 7). Where the articular surfaces were ankylosed, the synovial membrane as well as the capsular ligament were, as a rule, replaced by bone. In one case the capsular ligament was ossified while the synovial membrane was represented by a line resembling cartilage. In another the synovial membrane was apparently not affected, although there was osseous ankylosis of the adjacent joint.

While the changes of the synovial membrane were mainly exudative and proliferative, the changes of the articular cartilage were mostly degenerative. The appearance of the degeneration varied. In the early stages it manifested itself in a changed staining reaction. In this case the intercellular hyaline substance stained pinkish, while the nuclei gradually became smaller until they were represented by small granules of nuclear material, which later disappeared, leaving a homogeneous pinkish staining matrix. This process was seen, in many instances, on the articular surface while the remaining cartilage was apparently normal. In other cases it took place around blood vessels that budded into the articular cartilage from the subchondral bone. By this process the cartilage became vascularized (Figs. I and 2). In some of the cases two processes were present simultaneously, i.e., there was superficial degeneration of the cartilage, and at the same time vascularization from the subchondral bone.

In many of the long standing cases the cartilage was thickened and softened. In some of these the consistency was that of soft rubber while in others, farther advanced, the 
cartilage was soft and fibrillated. Microscopically, the cartilage was arranged in fibrils perpendicular to the articular surface (Fig. 3). In the cells near the surface the nuclei were nearly gone. They became larger as they approached the bone, and near the zone of calcification they appeared nearly normal. This process was produced experimentally by Cresswell in 1895 by means of long maceration and with the aid of pressure. He claims that chemically these fibrils are similar to connective tissue fibers.

Necrosis of the articular cartilage appeared in the form of diffuse superficial necrosis and as circumscribed areas within the articular cartilage. This was manifested by a disappearance of the nuclei and a pinkish staining matrix. It was seen in the early stages in which there was a reaction to a more severe irritation. Superficial necrosis in the form of crateriform erosions was more common. In these the cartilage had disappeared. In some of the cases the remains of the cartilage were in the form of a gelatinous mass. In others part of the cartilage was gone and the remainder was pinkish and homogeneous. In still others the cartilage was entirely gone, having been apparently liquefied and absorbed. Due to the fact that articular cartilage does not regenerate very readily, it is possible that some of these are the remains of a previous inflammation.

In some of the erosions the articular cartilage was partly replaced by loose vascular connective tissue. In others the replacement was partly by dense non-vascular connective tissue. In a few the cartilage was entirely replaced by what appeared to be fibro-cartilage. In the cases where there was ankylosis of the articular surfaces the cartilage was replaced by loose vascular connective tissue, by dense non-vascular connective tissue, by porous bone, and by dense bone, respectively. In one instance where the cartilage was replaced by loose vascular connective tissue there was formation of bone and proliferation of cartilage in this tissue (Fig. II). In another, where the cartilage was replaced by dense non-vascular connective tissue, there were areas of proliferating cartilage cells in this tissue. 
The erosions in the center of the tibial trochlear ridge are designated by certain anatomists as synovial fossæ. This would indicate that they consider them normal structures. In order to determine this point, a study was made of the joints of animals in utero as well as of older animals. In the cases designated as normal, the tibial trochlear ridges were found smooth and without a depression in the center. Some were found where the only variations from the normal were punctiform depressions on the ridge. A microscopic study of these so-called "synovial fossæ" showed that they are undoubtedly pathological erosions. Some of them show a reaction to severe irritation, while others show reaction to mild irritants. There were found several in which it appeared that there was an erosion that had healed. In these healed erosions the zone of provisional calcification was absent and the cartilage resembled fibro-cartilage instead of hyaline cartilage.

In some cases there were circumscribed areas of necrosis in the center of the articular cartilage. In a few of these the necrotic tissue was a homogeneous structureless mass. In most of them the necrotic areas were calcified. After decalcification these areas showed a homogeneous hyaline substance with numerous rounded bodies resembling "corpora amylacæ" (Fig. 4). These areas are designated by Eberlein as "lime points." According to him they are areas in which the cartilage has been invaded by subchondral marrow, and which later had undergone a condensing process, i.e., they are areas of ossification in which the process had become quiescent in the stage of condensing ostitis. They show in effect one of the sequelæ of necrosis. This is similar to necrosis in other tissues; particularly caseation necrosis, which often becomes calcified. They do not contain any bone.

In the subchondral bone enlargement of the marrow spaces by hyperemia and fibrinous exudate was the most marked feature in the early stages. A fibrinous exudate with numerous fibroblasts and congested blood vessels was found in the enlarged Haversian canals in some cases of long 
standing, even in those that showed fibrous ankylosis (Fig. IO). In two cases there were polymorphonuclear leucocytes in addition to the fibrin. Some of the enlarged Haversian canals were completely filled with endothelial cells, and some were completely filled with fibroblasts. In many cases these canals were filled with fibroblasts, congested blood vessels, fibrin, and lined by osteoblasts (Fig. II). In some apparently quiescent cases, or those that have reached the last stages, particularly where there was osseous ankylosis, these canals were filled with fatty marrow with slight hyperemia in certain instances (Fig. 8).

In some cases where the articular cartilage was eroded, the subchondral bone was normal. This was true in those that showed fibrillation of the articular cartilage, as well as those in which there was no fibrillation (Figs. 3 and 5). In some cases in which the erosion did not reach the subchondral bone, the latter was denser than usual. While it is possible that this was due to a condensing ostitis, this condition was not confined to the affected area, so that it is more probable that the bone was naturally denser in these animals. In many of the cases the erosin affected the subchondral bone, as well as the cartilage. In these instances part of the underlying bone was gone and its place was taken by granulation tissue, and in one case by granulation tissue in which these were circumscribed areas of polymorphonuclear leucocytes.

In one instance there were foci of necrosis in the subchondral bone. These apparently began immediately under the cartilage and spread towards the center. The overlying cartilage was degenerated, but intact.

Eburnation of the denuded articular ends of bones was seen in two instances: in the left stifle joint (Case 16) and in both intertarsal articulations (Case 42). Eburnation is described as occurring in freely movable joints. In the latter case the articulations between the central tarsus and the astragalus were affected. This joint is nearly devoid of motion. 
In most of the cases there were no apparent changes in the periosteum. In some of them the periosteum was slightly thickened by a proliferation of large, bluish staining cells arranged in rows parallel to the fibers of the attached ligaments. In one the periosteum was greatly thickened by connective tissue, and in three there was an ossifying periostitis.

To summarize the changes, the final stage of the process is an osseous ankylosis of two adjacent bones. This process may be confined to the joint, or it may be accompanied by a periarticular ossification. This is, in many cases at least, preceded by a fibrous ankylosis. The fibrous tissue may be dense, non-vascular, with or without areas of proliferating cartilage. It may also be loose, rich in fibroblasts, and richly supplied with blood vessels (Figs. 8 and I I). In one case there was beginning ossification in this tissue. This form of ankylosis in some instances apparently began in the joint by an organizing exudate. The proliferation of tissue apparently began in the synovial membrane or around the interosseous ligament. In most cases it was impossible to tell where this form of ankylosis began. Preceding this stage there is erosion of the articular cartilage, with or without involvement of the subchondral bone. These erosions began in the subchondral bone in some cases. In others it undoubtedly began in the joint sinus. In those that involved the bone, as well as the entire depth of the articular cartilage, it was impossible to determine the point of origin. The proliferation of the synovial membrane may start at any period of the process. The formation of villous tufts on the synovial membrane is so common that they have been considered as normally occurring "synovial villi." In this study normal synovial membranes have been encountered in which the surface was whitish, smooth, and shiny, similar to that of other serous membranes. The early changes are hyperemia and exudation on the synovial membrane, hyperemia and exudation in the marrow spaces with widening of these, and degeneration of the articular cartilage. These changes may 
take place at the same time or they may occur individually. The process may become quiescent at various stages.

The synovial membrane is the only structure in the immediate proximity of the joint sinus that is supplied with blood vessels. This makes the synovial membrane more resistant to irritation than the non-vascular articular cartilage. Regeneration of the articular cartilage does not take place very readily while all the structures of the synovial membrane regenerate with ease. For these reasons the same causative agent that would stimulate the synovial membrane to proliferation might produce degeneration and necrosis of the articular cartilage. The transition between the synovial membrane and the articular cartilage is gradual, so that there are blood vessels at the edge. This may account for the occurrence of the erosions a few millimeters from the articular border. Around the extreme articular border some of the cases studied show proliferative changes similar to those found on the synovial membrane.

Practically nothing new can be advanced regarding the point of origin of spavin, since it has been ascribed to nearly every structure encountered in the neighborhood of the hock joint. It was thought to arise from the ligaments, bursæ, tendons, and the synovial membrane around the hock joint. It was even thought that it originated from a gonitis. Finally, it was believed to originate from the articular cartilage and from the subchondral bone. Since Havemann's discovery of the erosions in the joint, the speculations centered around the question whether the development of spavin was from within outwards, or from the outside inwardly. Beginning with Gotti and affirmed by most veterinarians of to-day, the former view was considered the correct one.

In these cases, with three exceptions, all the bursæ were apparently normal. In those that showed pathological changes, they were not of longer standing than the changes in the joint. It is undoubtedly possible that a traumatic injury of any kind may produce an ossifying periostitis 
which may later spread to the synovial membrane and then to the joint. There is in this laboratory a dry specimen of a case of an ossifying periostitis not involving the joint. The coronary ring bone of the right fore leg in Case 37 and that of the right hind leg in Case 30 also illustrate this point. There are, however, numerous cases of spavin in which the periosteum is not involved, and, when involved, show changes that are less marked than those in the other structures of the joint. This is illustrated in many of the cases described in this paper, which shows conclusively that certainly not all cases of spavin originate in the periosteum. In many there were degeneration and erosions of the articular cartilage together with proliferation of the synovial membrane, without any affection of the bone. In these the zone of calcification was intact. In some the erosions began by a fibrinous exudate in the joint sinus. In these instances the point of origin was undoubtedly in the joint and not in the subchondral bone. In some of the cases the erosions began by vascularization of the articular cartilage. These blood vessels came from the subchondral bone. This makes it possible that in some instances the point of origin is in the subchondral bone. In one case there were necrotic foci in the subchondral bone while the articular cartilage showed degeneration. It seems that here the origin was in the subchondral bone.

The erosions in these cases are on opposing articular cartilages. This is explained more readily on the assumption of an intra-articular irritation than as a subchondral irritation. Nathan holds that these are due to subchondral infective foci. This would mean that the foci were by chance in corresponding areas of the opposing bones. The cases where the erosions are exactly opposite each other are too numerous to be due to chance. It is possible that an irritant on the surface of the articular cartilage may be sufficiently severe to call forth a vascularization of the cartilage from the subchondral bone. If this is so, it is possible that many erosions that appear to begin in the subchondral bone are in reality caused by an intra-articular severe irritant. 
Such an irritant on the cornea, particularly a bacterial irritant, will produce vascularization of the cornea. The cartilage is likewise a non-vascular tissue, and it may react to a severe irritant in the same manner as the cornea. The erosions around the interosseous ligaments seem to indicate that the irritant producing them is in the joint proper.

Since there are various forms of inflammations in the hock joint that may eventually lead to ankylosis and exostosis, it seems advisable to have the term spavin indicate any inflammation of the hock joint that may lead to ankylosis and exostosis. The meaning of the term spavin has been previously changed. As it stands to-day it does not include severe irritation in the joint which later terminates in ankylosis and exostosis.

That the erosive forms of arthritis in the hock joint are included in the term spavin is evidenced by the various descriptions of this condition, beginning with Havemann's finding of these erosions. It seems advisable to include the exudative forms of arthritis in the hock joint, since they too may lead, and often do lead, to ankylosis and exostosis.

The present views concerning the etiology of spavin are not entirely satisfactory. With few exceptions, mechanical irritation is considered as being the cause. It is thought to be brought about by. pressure on the articular ends, stretching of tendons and ligaments. The erosions are described as being punctiform in the early stages. It seems doubtful that pressure in a joint should be concentrated in an area a millimeter in diameter. In those cases in which there was fibrillation of the articular cartilage, there is experimental data to show that it might be produced by pressure. Even here, however, pressure alone does not seem to be sufficient to produce such changes. Traumatism is a satisfactory explanation only in those cases that apparently began with a periostitis or an open joint.

Considering the frequency of arthritis following diseases of other organs, - notably acute pneumonia, pericarditis, pleuritis, peritonitis, metritis, an ulcerated tooth, or other suppurating foci, - it seems possible that the true cause of 
many a lameness is overlooked. The history is often unsatisfactory. The lameness is often ascribed to a sprain where it may rather be a sequel of a forgotten inflammatory condition. Organisms may get into the circulation and finally lodge in the joints without producing any local lesion elsewhere in the body. The joints, not being richly supplied with blood, are favorable seats for multiplication of microorganisms.

Spavin is more common in some localities than in others. Here in Ithaca it is a common affection of horses. This has been ascribed to the hilly country. Dr. W. L. Williams claims that during his practice in the foothills of the Rocky Mountains spavin was rarely encountered. Certainly the Ithaca hills, then, cannot be the cause of the frequency of spavin.

Various authors claim that spavin is more common in young than in older animals. Spavin is said to be most common in horses between the ages of two and four years. The reason for this fact, advanced by many authors, is the nervous temperament of younger horses. It is because "they attempt their work more vigorously than older animals." This explanation does not seem to be very satisfactory. It seems possible that the reason spavin is less common in older animals is because of age immunity. Younger animals generally are more susceptible to infection than older ones. The nervous temperament may be a contributing factor.

Many of these cases were undoubtedly caused by intrauterine or umbilical infection. The variation of the lesions was apparently due to the variation of the resistance of the animals, the variation of the virulence of the cause, perhaps, and the variation in the ages of the processes. Case 22 is a notable example of well-advanced lesions caused by umbilical infection. A case similar to this one has been observed. It was about the same age, with a similar clinical history. A veterinarian ordered the destruction of the animal and the order was not followed. The animal recovered sufficiently to give eight years of valuable service. The dry specimen 
showed erosions in the right stifle and a spavin with articular and periarticular ankylosis of the left hock joint.

In both these cases the cause was apparently local infection resulting from umbilical infection. They show that it is possible for spavin to develop from umbilical infection.

Schofield in his study of joint ill in foals concludes that it is closely associated with a hemolytic streptococcus, in which case the infection is probably by ingestion, since these organisms were found in the milk of the dam. Other means of infection are, according to him, intra-uterine and through the unhealed navel. He illustrates cases that recovered and those that resulted in ankylosis.

Dr. W. L. Williams cites a case of a herd in which there were about fifty suckling foals. Many of the foals suffered from spavin, ring bone, and allied diseases. This herd was pasturing in a swamp. When the pasture was changed to dry land spavin ceased to exist in the herd. This case apparently corresponds to Saunier's "l'eparvin gras."

In these foals running about freely in a pasture the cause does not seem to be in stretching of tendons, overexertion, heavy loads, or even excessive pressure on the cartilages. On the moist pasture infection seems to be the more likely cause of the spavins. The fact that it disappeared from the herd after change of pasture would strengthen this view.

In many of these cases the pathological changes are similar to those caused by infection. A marked fibrinous exudate, for example, is as a rule caused by infection. In many of these cases this is the most conspicuous change. The villous tufts on the synovial membrane are similar to those commonly occurring on the peritoneal or pleural surfaces. In the latter cavities they are thought to be due to bacterial irritation, so that in the joint they are possibly of an infectious nature.

In many of the cases studied bacteria were found in the joints. In some they were obtained in pure culture, while in others there were mixed infections. In several instances where culture media inoculated from other organs of the body remained sterile, a growth was obtained from the joints. 
The various bacteria isolated were $B$. coli, staphylococci, streptococci, an unidentified rod-shaped organism in one case, and Bact. pyogenes in one case in a cow with suppurative mastitis in addition to joint lesions.

Lesions similar to most of those found in the cases studied were produced experimentally by Nathan. They were produced in dogs by intravenous inoculations of hemolytic streptococci, pneumococci, and staphylococci, respectively. In this series all the organisms produced practically the same changes, so that the lesions are not those due to a specific cause.

In a recent study of spontaneous chronic arthritis in swine, Sekiguchi and Irons found hemolytic streptococci in two, bacilli in nine, and a mixed infection of streptococci and bacilli in four cases. In two they found bacteria in smears, but not in culture, and in two they found no bacteria. They produced joint lesions in pigs by subcutaneous and intravenous inoculation of the organisms found.

The experimental data seem to strengthen the belief that many of the cases studied were caused by infection.

From a study of these cases the following conclusions seem justifiable :

I. That there are very commonly found in horses and cattle low-grade polyarticular inflammations, leading to erosions and ankylosis.

2. That in these cases the hock joints are the ones most often affected by the inflammations.

3. That it is advisable to have the term spavin indicate any inflammation of the hock joint leading to ankylosis.

4. That the origin of spavin may be in the joint proper as well as in the rubchondral bone.

5. That in many cases spavin is apparently caused by infection.

6. That the primary seat of erosions and ankylosis may be in any of the intertarsal as well as the tarso-metatarsal joints. 
7. That the so-called "synovial fossæ" are pathological erosions.

8. That the so-called "synovial villi" are, in many cases at least, pathological outgrowths caused by mild irritation.

9. That the so-called "lime points" in the articular cartilages are areas of necrosis in which calcification has taken place.

I0. That a periarticular ankylosis is, in some cases at least, due to an ossifying inflammation of the capsular ligament.

I I. That in the cases studied the osteoclasts do not play an important part in the rarefying ostitis.

[The author wishes to take this opportunity to thank Prof. S. H. Burnett, under whose supervision this work was done, for his encouragement and helpful criticisms. I am also indebted to him for selecting this subject, and for the gross description of Cases 17 and 37.] 


\section{BIBLIOGRAPHY.}

Abraham, P. S. Arthritis Deformans in the Horse. Dublin, r884. Aronsohn. Inaug. Diss. Giessen, 1893 .

Bartels. Viehzucht u. Thierheilk., 1843, i (cited by Aronsohn).

Büche, Karl. Inaug. Diss. Hanover, 1912 .

Bürki. Archiv. für Thierheilk., I905, xxxi, 241 .

Burnett, S. H. Outline of Lectures in Special Pathology. 1916, 53.

Clark, H. C. Journ. Am. Med. Assoc., 1917, lxix, 2099.

Cresswell, B. Journ. Anat. and Phys., 1895 (cited by Schäfer).

Dieckerhoff. Die Path. und Therap. d. Spates d. Pferde, 1875 .

Eberlein. Monatsh. f. prakt. Thierheilk., I898, ix, 49.

Engel, Hans. Inaug. Diss. Berlin, 1902.

Fröhner. Spezielle Chirurgie für Tierärzte, 1905, 256.

Gibson, Wm. A. Diseases of Horses. London, 1754, ii, 252.

Goldberg, S. A. Cornell Veterinarian, 1915, v, 90; Am. Vet. Rev., 1915, xlvii, 735 ; Report N.Y. State Vet. College at Cornell University, 1914-15, 142; Cornell Veterinarian, 1916, vi, 57.

Good and Smith. Bul. 204, Kentucky Ag. Expt. Station.

Gotti. Ricerche Sopra un lento Processo arthritis al Tarso del Cavalo. Bologna, 1880 .

Gray, de. The Complete Horseman and Expert Farrier. 1639, 324.

Hamilton, J. W. Ohio. Med. and Surg. Jour., 1860.

Harger, S. J. J. Am. Vet. Rev., Igor, xxv, 992.

Hertwig, F. Chirurgie für Thierärzte, I850 (cited by Eberlein).

Holth, H. Zeitschr. f. Infk. d. Haust., I908, iii, 155 .

Kärnbach. Monatsh. f. prakt. Thierhalk., 1905, xiv, 97; 1900, xi, 516.

Kitt, Th. Lehrbuch der pathologischen Anatomie der Haustiere, 1910, i, 404 .

Krueger. Archiv. f. Thierheilk., 1905, 295.

Lawrence, Richard. The Complete Farrier. $1850,77$.

Nathan, P. Wm. Journ. Med. Res., 1917, xxxvi, 187 .

Nichols and Richardson. Journ. Med. Res., 1909, xxi, 149.

Pflug. Spat. Encyklop. der gesammt. Thierheilk. u. Viehz., I892, ix.

Rvini, Carlo. Delle Infirmitadi De'caualli, 1602, 3 I4.

Schäfer, E. A. Microscopic Anatomy. 1912.

Schofield, F. W. Joint-ill in Foals. Toronto, 1916.

Schrader, G. W. Mag. f. d. gesammte Thierheilk., 1839, v, 95.

Schrader, Jr. Magaz. f. d. gesammte Thierheilk., I860, xxvi, I.

Sekiguchi and Irons. Journ. Inf. Dis., 191 7, xxi, 526.

Smith, F. Journ. Comp. Path. and Therap., 1893, vi, 1, 149, 195.

Stockfleth. Tidsskr. f. Veterin., 1868 (cited by Eberlein).

Taplin, Wm. Modern System of Farriery. I789, 55 .

Traeger. Magaz. f. d. gesammte Thierheilk., 1839, v, 205.

Urdiskie. Monatsh. f. prakt. Thierheilk., 1900, xi, 337 .

Ward, A. R. Cornell Veterinarian, I917, vii, 29.

Whitelocke. Sprains and Allied Injuries of Joints. I9ro.

Weichselbaum, A. Virch. Arch., I878, lxxiii, 46r.

Williams, Fischer, and Udall. Proc. A. V. M. A., 1905, xlii, 283.

Zalewsky. Monatsh. f. prakt. Thierheilk., I9OI, xii, 48r.

Ziegler, E. Virch. Arch., 1878, 1xxiii, 355 . 


\section{DESCRIPTION OF PLATES XI. AND XII.}

Plate XI., Fig. I. - Thickened area on articular cartilage with beginning erosion from the subchondral bone. Right tibial trochlear ridge. Case 5. $\times 29$.

A. Thickened area on articular cartilage.

B. Normal articular cartilage.

C. Degenerated articular cartilage.

D. Beginning erosion of the articular cartilage by vascularization from the subchondral bone.

E. Congested subchondral bone.

Fig. 2. - Beginning erosions from subchondral bone. Medial ridge of trochlear right femur. Case 22. $\times 20$.

A. Articular cartilage.

B. Areas where cartilage is being dissolved by fibrin and blood vessels.

C. Rarefied subchondral bone.

Fig. 3. - Erosion originating in the joint. Left astragalar trochlea. Case 35. $\mathrm{x} 20$.

A. Area where cartilage is absent.

B. Fibrillation of the remaining articular cartilage.

C. Subchondral bone apparently normal.

Fig. 4. - Calcified area of necrosis in the articular cartilage tibioastragalar articulation. Case 57. $\times 40$.
A. Calcified area of necrosis.
B. Degenerated articular cartilage.
C. Articular cartilage nearly normal.
D. Subchondral bone denser than normal.

Fig. 5. - Erosion originating in the joint. Right tibial trochlear ridge. Case 49. $\mathrm{x} 20$.

A. Area where cartilage is gone.

B. Remaining articular cartilage.

C. Pinkish staining homogeneous material in place of cartilage.

D. Normal subchondral bone.

Plate XII., Fig. 6. - Organizing fibrin on right patella. Case 22. $\times 25$.

A. Subchondral bone.

B. Articular cartilage.

C. Fibrous connective tissue.

D. Granulation tissue.

E. Fibrin.

Fig. 7. - Adhesions of different parts of the synovial membrane. Left patellar articulation. Case 16. 9/10 natural size.

A. Patellar articular surface.

B. Arborous film of blood vessels on the articular cartilage.

C. Band of connective tissue forming an adhesion between several parts of the synovial membrane and the patellar articular surface. 
D. Filliform and papilliform villous tufts on the synovial membrane.

E. Accessory cartilage of the patella.

F. Thickened capsular ligament.

Fig. 8. - Fibrous ankylosis that apparently began in the joint. Right calcaneo-astragalar articulation. Case 4I. $\times 30$.

A. Remaining cartilages on both articular surfaces.

B. Embryonal connective tissue and blood vessels in the joint sinus.

C. Subchondral bones.

FIg. 9. - Ossification in an organized fibrinous exudate on synovial membrane. Right stifle. Case 22. $\times 35$.

A. Island of bone.

B. Granulation tissue.

Fig. 10. - Enlarged Haversian canal. Left third tarsus. Case 37. $\times 250$.
A. Bony lamellæ.
B. Osteoblasts lining the Haversian canal.
C. Haversian canal containing fibrin and fibroblasts.

FIg. II. - Fibrous ankylosis in the articulation between the astragalus and central tarsus right hock. Case $4 \mathrm{r}$. $\times 75$.

A. Articular cartilage nearly normal.

B. Fibroblasts and blood vessels producing ankylosis of the joint.

C. Proliferating fibrocartilage in the ankylosis.

D. Formation of bone in the ankylosis.

E. Enlarged Haversian canals containing fibrin, fibroblasts, and congested blood vessels, and lined by osteoblasts.

F. Degenerated articular cartilage.

G. Exudate of fibrin in the joint sinus. 


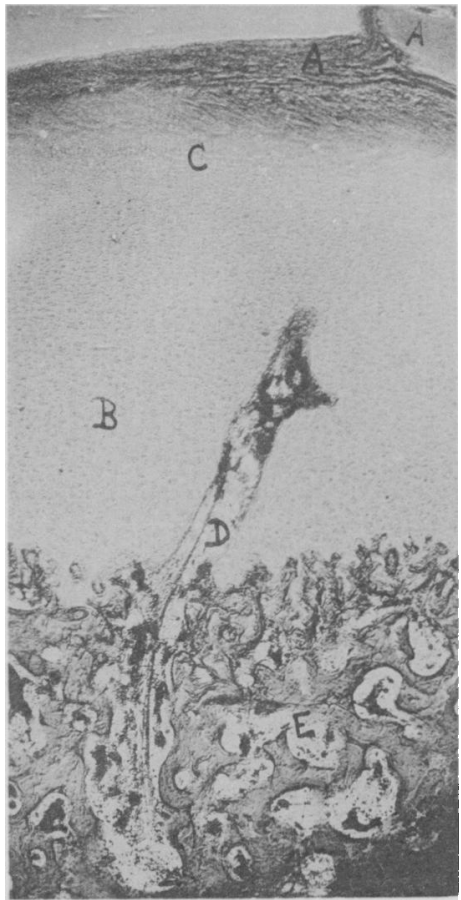

1

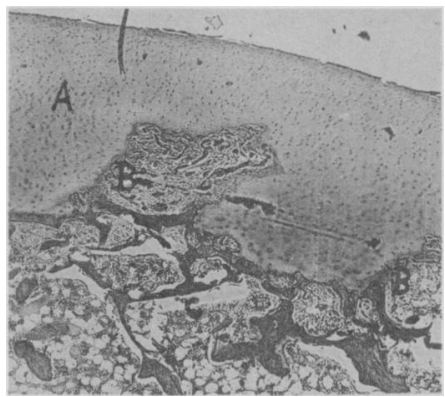

2

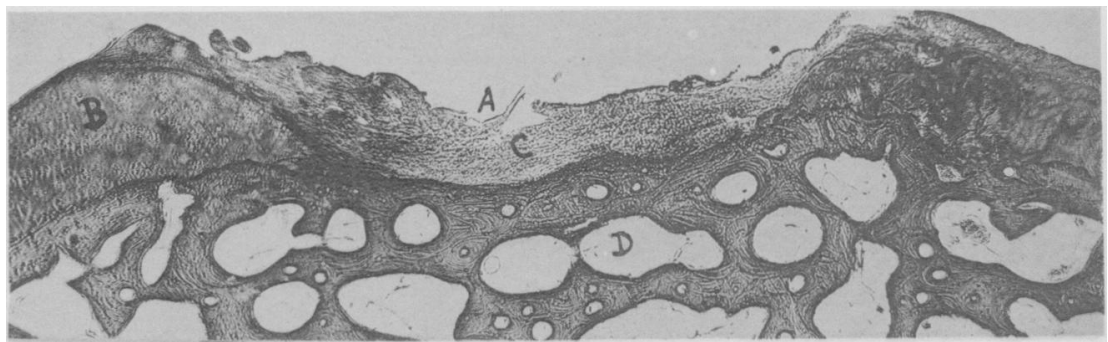

5

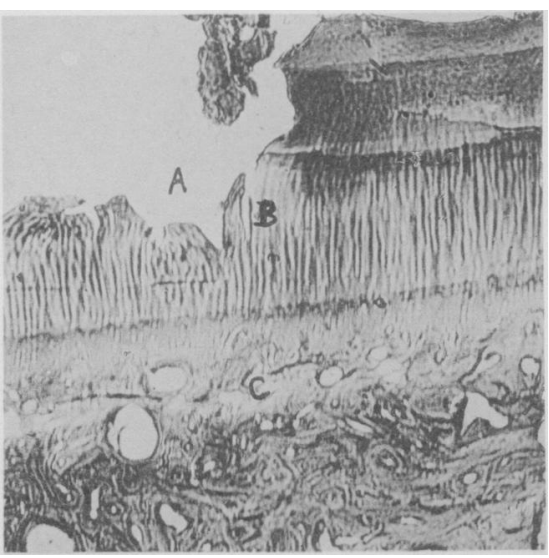

3

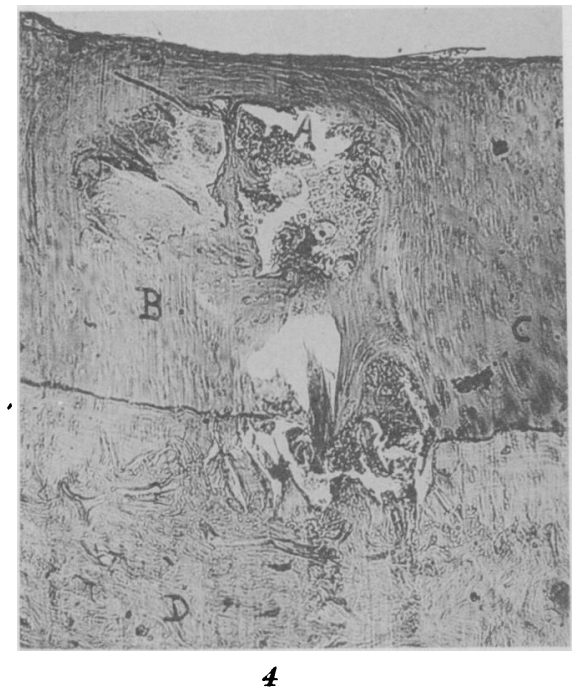



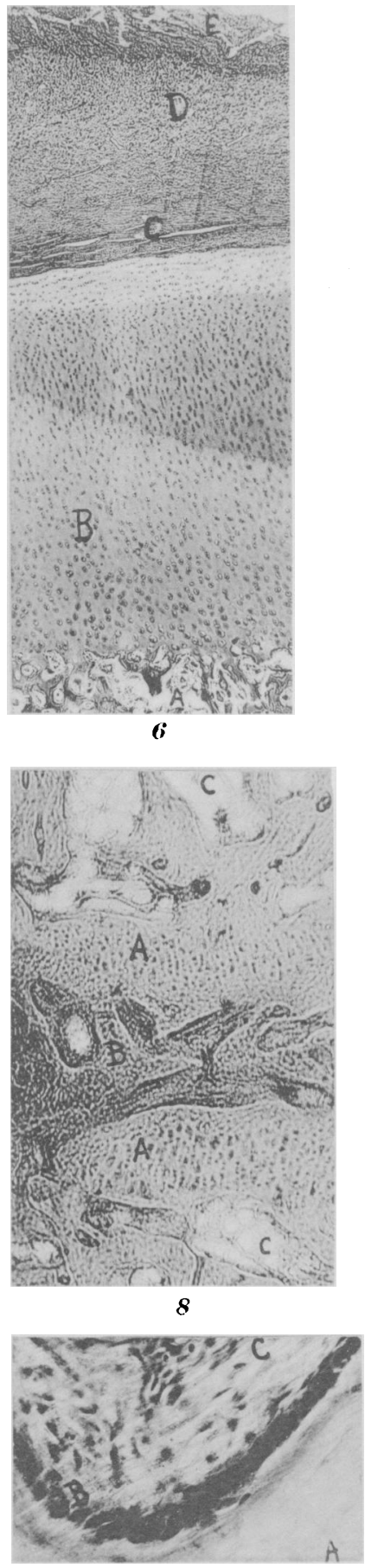

10

Goldberg.

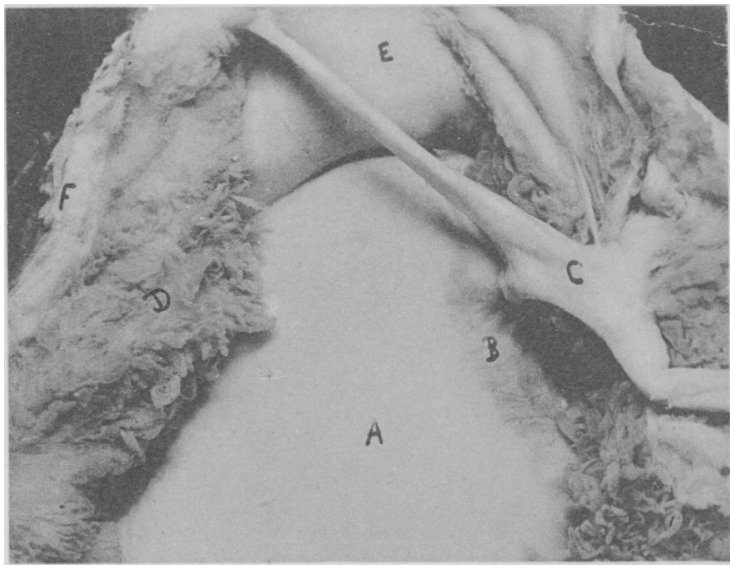

7

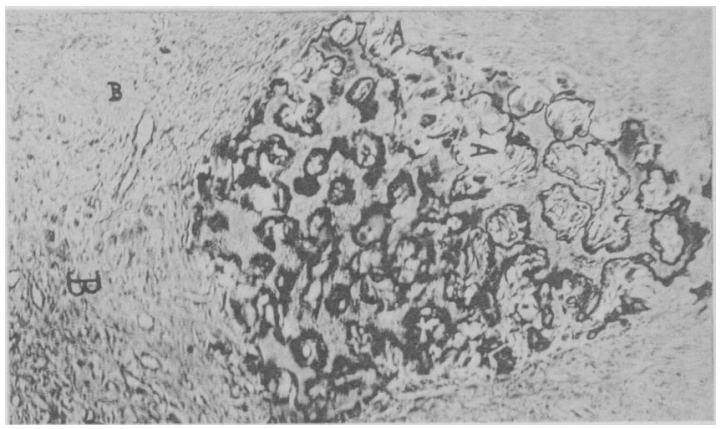

9

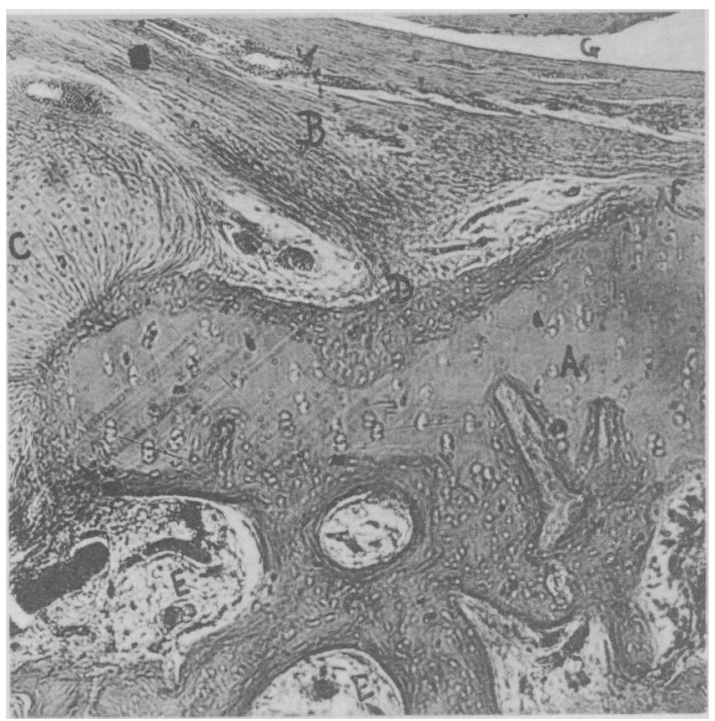

11 